\title{
Longitudinal Development of Specific and Functional Antibody in Very Low Birth Weight Premature Infants ${ }^{1}$
}

\author{
K. LYNN CATES, CYNTHIA GOETZ, NAOMI ROSENBERG, ALEX PANTSCHENKO, \\ JONELLE C. ROWE, AND MARK BALLOW \\ Department of Pediatrics, Divisions of Infectious Diseases [K.L.C., N.R.], Neonatology [C.G., J.C.R.], and \\ Clinical Immunology [A.P., M.B.], the University of Connecticut School of Medicine, Farmington, Connecticut
}

\begin{abstract}
We evaluated the formation of specific and functional antibody in preterm infants born weighing less than $1500 \mathrm{~g}$ (mean $1088 \mathrm{~g}$ ) and less than 32 wk gestational age (mean 28.8 wk). Plasma IgG antibody against tetanus and diphtheria toxoids were measured by an enzyme-linked immunosorbent assay. Opsonic activity of heat-inactivated plasma was measured using radiolabeled bacteria, adult polymorphonuclear leukocytes and exogenous human complement. In the presence of complement, the strain of coagulase negative staphylococcus used was opsonized by IgG antibody, and the strain of Escherichia coli by IgM. Geometric mean plasma levels of tetanus and diphtheria IgG antibody fell from birth to 4 months chronological age, but rose significantly by 9 months (approximately 2 months after the third dose of diphtheria, tetanus, pertussis vaccine). However, at 9 months they remained lower than the respective geometric mean levels in 9-month-old term infants (tetanus: $p<0.001$; diphtheria: $p=0.02$ ). The preterm infants' mean plasma IgG staphylococcal opsonic activity fell from birth to 2.5 months, but by 9 months was comparable to that of term infants of the same age. Mean IgM opsonic activity for $E$. coli was very low at birth in both preterm and term infants. It rose with chronological age, correlating with the rise in total $\operatorname{IgM}(r=0.48, p<$ $0.001)$ and by 9 months the mean preterm and term infants' levels of IgM opsonic activity for $E$. coli were comparable. In the newborn period, the preterm infants' levels of plasma IgG tetanus and diphtheria antibody, but not IgG staphylococcal opsonic activity, correlated with their mothers' levels (tetanus: $r=0.84, p<0.001$; diphtheria: $r=0.86$, $p<0.001$; staphylococcal: $r=0.17, p=0.38$ ). Placentally transferred maternal tetanus, diphtheria, and opsonic staphylococcal IgG antibody did not inhibit the infants' subsequent antibody responses to the respective antigens. We conclude that the ability of preterm infants to form specific and functional antibody may place them at lower risk for infection than might be expected from their very low plasma levels of total IgG and IgM antibodies. In addition, the good correlation between newborn and maternal plasma levels of IgG antibody to tetanus and diphtheria toxoids, but not IgG-dependent staphylococcal opsonic activity, suggests preferential transport of some IgG antibod-
\end{abstract}

Received January 9, 1987; accepted August 25, 1987.

Supported in part by Grant HD-16481 from the Institute of Child Health and Human Development of the National Institutes of Health, and by Ross Laboratories, Columbus, $\mathrm{OH}$

Correspondence K. Lynn Cates, M.D., Department of Genetics, Washington University School of Medicine, Box 8031, 4566 Scott Avenue, St. Louis, MO 63110.

' Presented in part at the 26th Interscience Conference on Antimicrobial Agents and Chemotherapy, 1 October 1986, New Orleans, LA. ies across the placenta or, alternatively, that the function of some IgG antibodies may be impaired by placental transport. (Pediatr Res 23: 14-22, 1988)

\section{Abbreviations}

NICU, neonatal intensive care unit

VLBW, very low birth weight

DTP, diphtheria, tetanus, pertussis

ELISA, enzyme-linked immunosorbent assay

TIG, tetanus immune globulin

PMN, polymorphonuclear leukocytes

cfu, colony forming units

PBS, phosphate-buffered saline

gel HBSS, Hanks' balanced salt solution with $1.0 \%$ gelatin cpm, counts per minute

PHS, pooled human serum

Previously we reported that VLBW premature infants (less than $1500 \mathrm{~g}$ birth weight) develop severe prolonged hypogammaglobulinemia in the first few months of life $(1,2)$. From the time of discharge from the nursery until 10 months chronological age, these infants' overall rate of infection and their rate of lower respiratory tract infection, in particular, were higher than those in term infants. However, although their IgG levels are lowest after discharge from the NICU, only two of the 89 premature infants enrolled in our study to date have developed a serious bacterial infection after discharge. Most patients with congenital immune deficiency who have circulating levels of immunoglobulin as low as those seen in preterm infants have a markedly increased susceptibility to recurrent and severe bacterial infections, and require maintenance immune serum globulin replacement therapy $(3,4)$. However, a small group of patients with hypogammaglobulinemia, those with transient hypogammaglobulinemia of infancy, do well without replacement therapy (5). The ability of patients with this syndrome to form antibody in response to antigenic challenge distinguishes them from other patients with congenital (4) and acquired hypogammaglobulinemia (3), and may help explain why they do not usually require immune serum globulin therapy. Herein, we set out to determine whether or not, despite their very low plasma levels of immunoglobulin $G, M$, and $A(1)$, premature infants could respond to antigenic challenge with the formation of specific and functional antibodies. We measured their plasma $\operatorname{IgG}$ antibody responses to immunization with tetanus and diphtheria toxoids, their IgGdependent opsonic activity for coagulase negative staphylococcus, and their IgM-dependent opsonic activity for Escherichia coli. 


\section{MATERIALS AND METHODS}

Study population. After obtaining informed written parental consent, we enrolled infants with birth weights less than $1500 \mathrm{~g}$ who were appropriate for gestational age (6) and were either inborn or transferred within the first $24 \mathrm{~h}$ of life to the NICU at the University of Connecticut Health Center. Infants with major congenital or metabolic defects or intrauterine infections were not enrolled in the study. To date, 39 infants have been followed until 12 months, and another 12 until at least 6 months chronological age. Because the infants reported herein are part of an ongoing study to determine the effects of feeding formula versus human milk on the development of the immune system, two infants who developed necrotizing enterocolitis, and five who were unable to tolerate enteral feeds by 28 days of life were withdrawn from the study. Two other babies were excluded after double-volume exchange transfusions. When blood transfusions were required, red blood cells were tightly packed (hematocrit greater than $80 \%$ ) and resuspended in saline in order to reduce the amount of immunoglobulin in the transfusion.

The mean $( \pm \mathrm{SD})$ gestational age was $28.8( \pm 1.8)$ wk (median 29; range 24-32) for the 51 infants followed until at least 6 months of age. The mean birth weight was $1088( \pm 204) \mathrm{g}$ (median 1115; range 659-1439). There was a good correlation between gestational age and birth weight $(r=0.80, p<0.001)$. There were 30 males and 21 females. Forty-six infants were Caucasian and five were black. The pattern of infection in the first 43 infants enrolled has been reported previously (1). Subsequently, of the 89 babies enrolled to date, one baby with severe, oxygen-dependent bronchopulmonary dysplasia died at 5.5 months of age with pneumococcal sepsis and respiratory syncytial virus pneumonia. Another infant developed pneumococcal meningitis at 4.5 months of age and recovered without sequelae.

Beginning in the 1 st wk of life (median $=$ day 6 ), heparinized blood samples were obtained by heel stick every 2 wk until discharge from the NICU. Infants were seen in the Neonatal Follow-up Clinic at the University of Connecticut Health Center at approximately 4, 6, and 10 months chronological age. Heparinized blood was obtained by venipuncture at follow-up clinic visits. Plasma was stored at $-70^{\circ} \mathrm{C}$ in small aliquots. Plasma was used instead of serum to allow the recovery of lymphocytes for other studies of the immune system. We have found that the antibody concentrations and function measured in this study are comparable in plasma and serum (Ballow M, Cates KL, unpublished data).

After informed consent was obtained from the parents, plasma samples also were obtained from 10 healthy term infants in the 1st wk of life, and from 37 others at 9 to 10 months of age. All 9- to 10-month-old term infants had received three doses of DTP vaccine.

DTP immunization. The age at the time the preterm infants were immunized with DTP vaccine varied because of the infants' clinical condition. The first dose was given at a mean $( \pm \mathrm{SD})$ of $69( \pm 24)$ days chronological age (median 62 ; range $41-170$ ), the second at $142( \pm 38$ ) days (median 140; range 84-324), and the third at $201( \pm 31)$ days (median 197; range 140-328). Eight infants did not receive three full doses of vaccine. In six of these infants, one of the three injections (five first dose; one third dose) consisted of only one-half or the recommended dosage. Two other infants received half doses for two of their three injections (first and second; first and third).

Tetanus and diphtheria toxoid IgG antibody determination. IgG antibodies to tetanus and diphtheria toxoids were measured by an ELISA. Tetanus toxoid IgG antibodies were quantified as previously described (7) with minor modifications. Dilutions (0.025 to 0.0018 tetanus antitoxin $\mathrm{U} / \mathrm{ml}$ ) of TIG (human HyperTet; $250 \mathrm{U} / \mathrm{ml}$; Cutter Laboratories, Berkeley, CA) were used for the standard curve. Plasma samples from infants $<200$ days chronological age initially were diluted 1:5, and those $>200$ days, 1:10. Five 2-fold serial dilutions were used to construct the dilution curve. The concentrations of IgG antibody to tetanus toxoid $(\mathrm{U} / \mathrm{ml})$ in the infants' plasma samples were calculated by computer from the linear portion of the standard curve by polynomial regression. The lower limit of sensitivity of the assay was $0.01 \mathrm{U} / \mathrm{ml}$. A human serum pool was assayed on each plate as an internal control. The coefficient of variation was $10.1 \%$ (7).

IgG antibody to diphtheria toxoid (refined concentrate, preservative free; Wyeth Laboratories, Marietta, PA) was quantified by ELISA as for tetanus antibodies except that, because of the lack of availability of a standardized human antiserum, PHS derived from 10 healthy adults was used for the standard curve. The PHS contained 0.96 diphtheria antitoxin $\mathrm{U} / \mathrm{ml}$ (kindly measured by Dr. George R. Siber, the Massachusetts Public Health Biologic Laboratories, Boston, MA). Six 2-fold serial dilutions (1:50 to $1: 1600)$ of the standard PHS pool and infant plasma samples were tested. The area under the dilution curve for PHS and each infants' sample was calculated as described by Sedgwick et al. (7) and Sparks and Ballow (8). The area under the curve for PHS was normalized to $1000 \mathrm{U} / \mathrm{ml}$ (arbitrary units). The amounts of IgG antibody to diphtheria toxoid in the infants' plasma samples were expressed as a percentage of that in the PHS and ( $1 \%$ corresponding to 0.0096 , or approximately $0.01 \mathrm{U} / \mathrm{ml}$ ). The lower limit of sensitivity of this assay was $1 \%$ of the PHS. The coefficient of variation was $10.8 \%$ for the reproducibility of one sample on different days and different microtiter plates.

Determination of total plasma IgG and IgM. Total plasma IgG and IgM concentrations were measured by ELISA (1).

Determination of opsonic activity. Opsonic activity was measured by a modification of the methods previously described by Peterson et al. (9) and Cates et al. (10) for measuring uptake of radiolabeled bacteria by PMN. Two organisms were chosen for opsonic studies based on 1) their ability to resist killing by serum or plasma alone, in the absence of PMN (i.e. serum resistance), 2) their ability to be opsonized well by plasma from most adults, and 3) their requirement for heat-stable opsonins (most likely immunoglobulin), in addition to complement. The last requirement was necessary since the purpose of our study was to evaluate the development of functional antibody, not complement, in premature infants. Studies of complement have been performed in this population by other investigators $(11,12)$.

The strain of coagulase negative staphylococcus used was a clinical isolate derived from the blood of a septic premature infant in the NICU at the University of Connecticut Health Center. It was identified as coagulase negative staphylococcus by standard techniques (Ref. 13, identification kindly performed by Dr. Richard C. Tilton, Clinical Microbiology Laboratory, the University of Connecticut Health Center). We selected it from among five clinical isolates of coagulase negative staphylococcus because its uptake by human PMN was more dependent on a heat-stable plasma factor, in addition to complement, than the other strains.

The test organism was grown overnight on Mueller-Hinton agar (Regional Media Laboratories, Lenexa, KS) and was stored in small aliquots in skim milk at $-70^{\circ} \mathrm{C}$. The night before the assay, a portion of skim milk was subcultured onto MuellerHinton agar and incubated aerobically overnight at $37^{\circ} \mathrm{C}$. The following morning, a large loopful of organisms was inoculated into $10 \mathrm{ml}$ of Mueller-Hinton broth (Beckton Dickinson, Cockeysville, MD) and $150 \mu \mathrm{l}$ of methyl $\left[{ }^{3} \mathrm{H}\right]$ thymidine (specific activity, $5 \mathrm{Ci} / \mathrm{mmol}$; Amersham Corporation, Arlington Heights, IL) were added. The organism was grown for 2.5 to $3 \mathrm{~h}$ in a shaking $37^{\circ} \mathrm{C}$ water bath $(100$ cycles/min) to a concentration of approximately $8 \times 10^{8} \mathrm{cfu} / \mathrm{ml}$. The radiolabeled bacteria were washed twice with PBS (pH 7.4) and resuspended in PBS to a final concentration of approximately $2 \times 10^{9} \mathrm{cfu} / \mathrm{ml}$ as determined by spectrophotometry and confirmed by colony counts. The final suspension of organisms had approximately $7 \times 10^{5}$ $\mathrm{cpm} / \mathrm{ml}$. 
The other organism used was a strain of Escherichia coli, serotype 022:H 16 (generously provided by Dr. Paul G. Quie, the University of Minnesota Hospitals, Minneapolis, MN). It was stored in skin milk at $-70^{\circ} \mathrm{C}$. Two nights before the assay, a portion of skim milk was cultured onto Mueller-Hinton agar and incubated aerobically overnight at $37^{\circ} \mathrm{C}$. The following evening, 20 colonies were touched with a loop and inoculated into $10 \mathrm{ml}$ of Mueller-Hinton broth and the culture was incubated aerobically overnight (approximately $18 \mathrm{~h}$ ) at $37^{\circ} \mathrm{C}$. On the morning of the assay, $1.5 \mathrm{ml}$ of the overnight culture was inoculated into $13.5 \mathrm{ml}$ of Mueller-Hinton broth, and $35 \mu \mathrm{l}$ of methyl $\left[{ }^{3} \mathrm{H}\right]$ thymidine were added. The organism was grown for 2.5 to $3 \mathrm{~h}$ in a shaking $37^{\circ} \mathrm{C}$ water bath $(60$ cycles $/ \mathrm{min})$ to a concentration of approximately $8 \times 10^{8} \mathrm{cfu} / \mathrm{ml}$. The radiolabeled bacteria were washed twice with PBS and resuspended in PBS to a final concentration of approximately $2 \times 10^{9} \mathrm{cfu} / \mathrm{ml}$ as determined by spectrophotometry and confirmed by colony counts. The final suspension of organisms had approximately $9 \times 10^{5} \mathrm{cpm} /$ $\mathrm{ml}$.

Human PMN were isolated daily from heparinized peripheral venous blood of healthy adult volunteers as previously described (10), and resuspended to a final concentration of $10^{7}$ cells per $\mathrm{ml}$ in HBSS (Gibco Laboratories, Grand Island, NY) with $1 \%$ gelatin HBSS (Becton Dickinson, Cockeysville, MD).

The babies' plasma samples contained a variable amount of complement activity because they could not always be frozen at $-70^{\circ} \mathrm{C}$ immediately after sampling. Thus, all samples were heatinactivated at $56^{\circ} \mathrm{C}$ for $30 \mathrm{~min}$ before use and then tested for opsonic activity in the presence of exogenous human complement. The source of complement was serum from an adult with common variable hypogammaglobulinemia (serum IgG: $22 \mathrm{mg} /$ dl, IgM: $14 \mathrm{mg} / \mathrm{dl}$, IgA: $8 \mathrm{mg} / \mathrm{dl}$ ), but normal total hemolytic complement activity [CH50;277 hemolytic units (normal 193 to $361 \mathrm{U})]$. This serum was stored in small portions at $-70^{\circ} \mathrm{C}$.

Radiolabeled organisms were preopsonized in a reaction mixture containing $50 \mu \mathrm{l}$ of radiolabeled staphylococci or $E$. coli, $12.5 \mu \mathrm{l}$ of complement, and $12.5 \mu \mathrm{l}$ of the plasma sample to be tested for the staphylococcal assay (final complement and plasma concentrations: $2.5 \%$ each) or $25 \mu \mathrm{l}$ of complement and $50 \mu \mathrm{l}$ of plasma to be tested for the $E$. coli assay (final complement concentration: $5 \%$; final plasma concentration: $10 \%$ ), and sufficient gel HBSS to bring the final volume to $500 \mu \mathrm{l}$. After 5 min incubation in a $37^{\circ} \mathrm{C}$ shaking water bath, the preopsonized bacteria were centrifuged at $1500 \times g$ for $15 \mathrm{~min}$ at $4^{\circ} \mathrm{C}$. The supernate was discarded, and the organisms were resuspended in $1 \mathrm{ml}$ of gel HBSS to a density of $10^{8} \mathrm{cfu} / \mathrm{ml}$.

The phagocytosis mixture consisted of $100 \mu \mathrm{l}$ of preopsonized radiolabeled staphylococci or E. coli $\left(10^{8} \mathrm{cfu} / \mathrm{ml}\right)$, and $100 \mu \mathrm{l}$ of the PMN suspension $\left(10^{7} / \mathrm{ml}\right)$, giving a final ratio of bacteria to PMN of 10:1. Organisms that had been preopsonized with each plasma sample were tested in triplicate pairs with PMN, and in a control pair without PMN. The tubes were incubated in a $37^{\circ}$ $\mathrm{C}$ shaking water bath $(100 \mathrm{cycles} / \mathrm{min}$ for staphylococci and 60 cycles/min for $E$. coli) for $15 \mathrm{~min}$ for the staphylococcal assay, and $12 \mathrm{~min}$ for the $E$. coli assay. The reaction was stopped by adding $3 \mathrm{ml}$ of iced PBS to each tube. Differential centrifugation was performed by spinning one tube of each pair at $125 \times \mathrm{g}, 4^{\circ}$ $\mathrm{C}$ for $5 \mathrm{~min}$ to pellet PMN and intracellular organisms (slow spin), and the other tube of the pair at $1500 \times g$ for $15 \mathrm{~min}$ to pellet all the organisms (fast spin). Uptake of radiolabeled bacteria by PMN was quantitated as previously described (10) by calculating the ratio of PMN-associated counts in the pellet from the slow spin to total bacteria-associated counts in the pellet from the fast spin. To control for day to day variability, opsonic activity of the test plasma was expressed as a percent of the uptake of bacteria induced by opsonization with PHS, in the presence of exogenous complement. Uptake induced by the respective concentrations of PHS plus complement for each organism (as noted above) was assigned an arbitrary value of $100 \%$ since it approximated the upper limit of the assays (mean \pm SD of 58 staphylococcal experiments was $75.1 \pm 7.5 \%$ and for $27 \mathrm{E}$. coli experiments was $51.7 \pm 11.6 \%$ uptake of total $\mathrm{cpm}$ added). When complement alone was used as an opsonin, the mean of 53 staphylococcal experiments was $17.2 \pm 11.8 \%$ and for $27 \mathrm{E}$. coli experiments was $4.0 \pm 2.9 \%$ of control uptake. The coefficient of variation when one sample was tested repeatedly on different days with PMN from different donors was $10.0 \%$ for staphylococcal experiments, and $13.4 \%$ for $E$. coli experiments. Opsonic activity of individual healthy adults was $83 \pm 11 \%$ control uptake for coagulase negative staphylococcus $(n=11)$, and $109 \pm 13 \%$ for $E$. coli $(n=10)$.

Statistics. Statistical analyses were performed on the Apple IIe computer. Simple linear regression and the Student's $t$ test were performed using the Stats Plus program. A $t$ test for paired samples was used when testing infant: mother pairs, or changes in individual infants' values over time. The $t$ test for unpaired samples was used for comparing the mean or geometric mean values of different groups. Log transformation was performed on the total plasma IgG and IgM, and tetanus and diphtheria IgG concentrations, and geometric means were used. Results of the opsonic assays are expressed as arithmetic means.

\section{RESULTS}

IgG antibody to tetanus and diphtheria toxoids. As has been reported (15), we found no difference in the geometric mean values of antibody responses to tetanus or diphtheria toxoids among the eight infants who had received half doses of DTP vaccine for one or two of their injections, and those of the 22 infants who had received three full doses of vaccine. Plasma samples were available for four of the five infants who received half doses of vaccine for the first injection. Their geometric mean tetanus and diphtheria toxoid IgG antibody levels after the first dose were comparable to those of the 21 infants who had received full doses (tetanus: 0.024 versus $0.028 \mathrm{U} / \mathrm{ml}, p=0.68$; diphtheria: 2.3 versus $6.0 \%, p=0.27$ ). Similarly, the antibody levels for the four infants who had received half doses and whose plasma was available after the second dose of vaccine, were comparable to those of the 20 infants who had received two full doses (tetanus: 0.037 versus $0.047 \mathrm{U} / \mathrm{ml}, p=0.61$; diphtheria: 21.1 versus $17.1 \%$, $p=0.68)$. After the third dose of vaccine, plasma was available on all eight infants who had received one $(n=6)$ or two $(n=2)$ half doses, and on 22 infants who had received three full doses. Again, the antibody concentrations were comparable for the two groups (tetanus: 0.108 versus $0.089 \mathrm{U} / \mathrm{ml}, p=0.55$; diphtheria: 31.4 versus $32.9 \%, p=0.55$ ). Therefore, for purposes of analysis, data from the infants who had received one or two half doses were combined with those of the infants who had received three full doses of DTP vaccine.

Changes with age in geometric mean IgG antibodies to tetanus and diphtheria toxoid are shown in Tables 1 and 2 and Figures 1 and 2. As can be seen in Table 1 and Figure 1 , in the first 2 wk of life, the preterm infants' geometric mean tetanus IgG antibody level is lower than that of their mothers, but the difference is not significant $(p=0.06)$. The geometric mean level of tetanus IgG antibody fell from the newborn period to reach its lowest point at 4 to 6 months chronological age. It rose significantly from 6 to 9 months ( $p=0.001)$, after the third dose of vaccine. However, at 9 months chronological age, the preterm infants' geometric mean level of IgG antibody to tetanus toxoid was significantly lower than that of their mothers $(p<0.001)$ or of 9-month-old term infants $(p<0.001)$.

As noted above ("Materials and methods"), the ELISA assay used to measure IgG antibody to tetanus toxoid was standardized with TIG of known toxin neutralizing activity. Tetanus antitoxin levels of $>0.01 \mathrm{U} / \mathrm{ml}$ as measured by tetanus toxin neutralization assays correlate with protection (16). Nine of our infants had one tetanus $\mathrm{IgG}$ level of $0.01 \mathrm{U} / \mathrm{ml}$, and another three infants had a level of less than $0.01 \mathrm{U} / \mathrm{ml}$ as measured by ELISA on one of their plasma samples. Five of the nine samples with levels of 
Table 1. Tetanus IgG concentrations

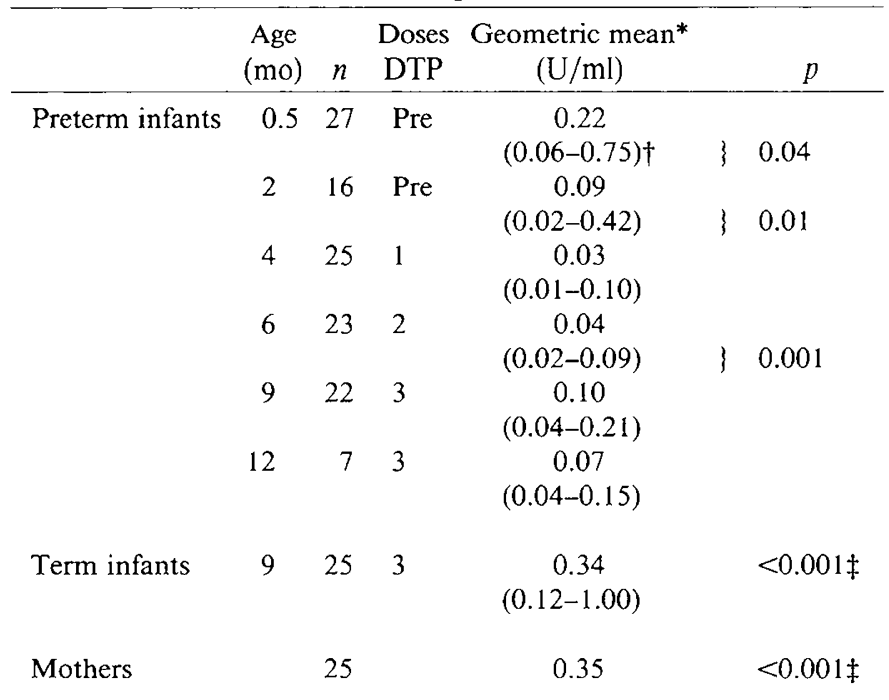

$(0.04-3.25)$

* Measured 2 or more wk after the indicated dose of vaccine.

$\dagger$ The ranges in parentheses were determined by taking the antilog of (mean logarithm \pm 1 SD of the logarithms).

$\ddagger$ Compared with 9 -month-old preterm infants.

Table 2. Diphtheria IgG concentrations

\begin{tabular}{|c|c|c|c|c|c|c|}
\hline & $\begin{array}{l}\text { Age } \\
(\mathrm{mo})\end{array}$ & $n$ & $\begin{array}{l}\text { Doses } \\
\text { DTP }\end{array}$ & $\begin{array}{c}\text { Geometric } \\
\text { mean* }\end{array}$ & & $p$ \\
\hline \multirow[t]{6}{*}{ Preterm infants } & 0.5 & 28 & Pre & $\begin{array}{l}17.9 \dagger \\
(5.0-64.4) \ddagger\end{array}$ & \} & 0.009 \\
\hline & 2 & 16 & Pre & $\begin{array}{l}5.7 \\
(1.2-26.8)\end{array}$ & & \\
\hline & 4 & 25 & 1 & $\begin{array}{l}5.4 \\
(1.0-29.0)\end{array}$ & \} & 0.03 \\
\hline & 6 & 23 & 2 & $\begin{array}{l}16.6 \\
(3.0-92.3)\end{array}$ & \} & 0.17 \\
\hline & 9 & 22 & 3 & $\begin{array}{l}30.9 \\
(8.7-109.4)\end{array}$ & & \\
\hline & 12 & 7 & 3 & $\begin{array}{l}30.7 \\
(16.3-57.9)\end{array}$ & & \\
\hline Term infants & 9 & 25 & 3 & $\begin{array}{l}67.6 \\
(23.8-192.3)\end{array}$ & & $0.02 \S$ \\
\hline Mothers & & 25 & & $\begin{array}{l}18.7 \\
(6.3-55.8)\end{array}$ & & $0.5 \S$ \\
\hline
\end{tabular}

* Measured 2 or more wk after the indicated dose of vaccine.

$\dagger$ Results are expressed as a percent of a normal human serum pool (see text).

$\ddagger$ The ranges in parentheses were determined by taking the antilog of (mean logarithm $\pm 1 \mathrm{SD}$ of the logarithms).

$\S$ Compared with 9-month-old preterm infants.

$0.01 \mathrm{U} / \mathrm{ml}$ were obtained just before the second dose of DTP, three after the second, and only one was obtained after the third dose. Plasma samples were available on eight of nine mothers of these infants, and they had a median tetanus $\mathrm{IgG}$ level of 1.04 $\mathrm{U} / \mathrm{ml}$ (range 0.48 to $2.46 \mathrm{U} / \mathrm{ml}$ ). Two of the three infant samples with levels less than $0.01 \mathrm{U} / \mathrm{ml}$ were obtained before the first dose of vaccine, and the mothers of both infants also had levels of less than $0.01 \mathrm{U} / \mathrm{mI}$ (the lower limit of the assay). The third infant sample with a level of $<0.01 \mathrm{U} / \mathrm{ml}$ was obtained on day 78 of life, 22 days after the first dose of vaccine. This infant's mother had a level of $0.74 \mathrm{U} / \mathrm{ml}$.

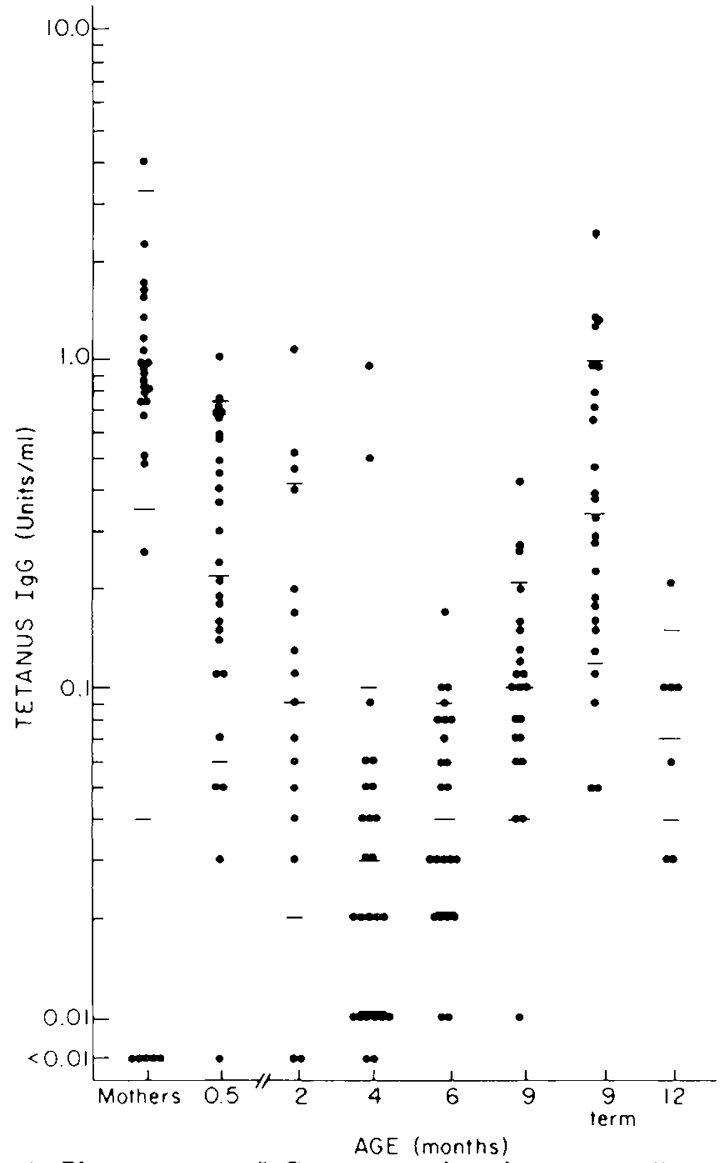

Fig. 1. Plasma tetanus $\operatorname{IgG}$ concentrations in very small premature infants $(<1500 \mathrm{~g})$, in their mothers, and in 9-month-old term infants. Bars represent geometric mean $\pm \mathrm{SD}$. Preterm infants 0.5 and 2 months of age had received no DTP immunizations; those 4 months had received one dose, those 6 months, two doses and those 9 and 12 months, three doses, respectively. All 9-month-old term infants had received three doses of DTP vaccine.

In the first 2 wk of life, the preterm infants had a geometric mean diphtheria IgG antibody level comparable to that of their mothers (Table 2). The preterm infants' geometric mean diphtheria IgG level fell and was lowest at 2 to 4 months chronological age, but rose significantly after the second dose of DTP vaccine (6-month sample) to a level comparable to that seen in the first 2 wk of life $(p=0.38)$ and to that of the mothers $(p=0.5)$. However, even at 9 and 12 months, the preterm infants' diphtheria $\operatorname{IgG}$ level was lower than that of 9-month-old term infants $(p=0.02)$.

A level of 0.01 diphtheria antitoxin $\mathrm{U} / \mathrm{ml}$ measured by toxin neutralization assays corresponds with protection (17). The lower limit of the ELISA assay we used for determining diphtheria IgG antibody was $1 \%$ of the activity of PHS, which contained 0.96 diphtheria antitoxin $\mathrm{U} / \mathrm{ml}$. Therefore, the lower limit of the assay corresponded to approximately 0.01 diphtheria antitoxin $\mathrm{U} / \mathrm{ml}$. Nine infants had diphtheria IgG antibody levels that were below the level of detection of our assay, two just before the first dose, three just before the second dose, and four before the third dose. The median diphtheria IgG antibody level in the seven mothers whose plasma was available was $13.8 \%$ (range 2.1 to $255 \%$ ), six of seven had levels of $20.6 \%$ or less.

There was no correlation between gestational age and plasma tetanus $\operatorname{IgG}(r=0.214, p=0.283)$, or diphtheria $\operatorname{IgG}$ values $(r$ $=0.155, p=0.435$ ) in the first 2 wk of life. However, there was a very good correlation between paired maternal and preterm infant tetanus or diphtheria IgG antibody levels in the newborn period (tetanus: $n=18$ pairs, $r=0.84, p<0.001$; diphtheria: $n$ 


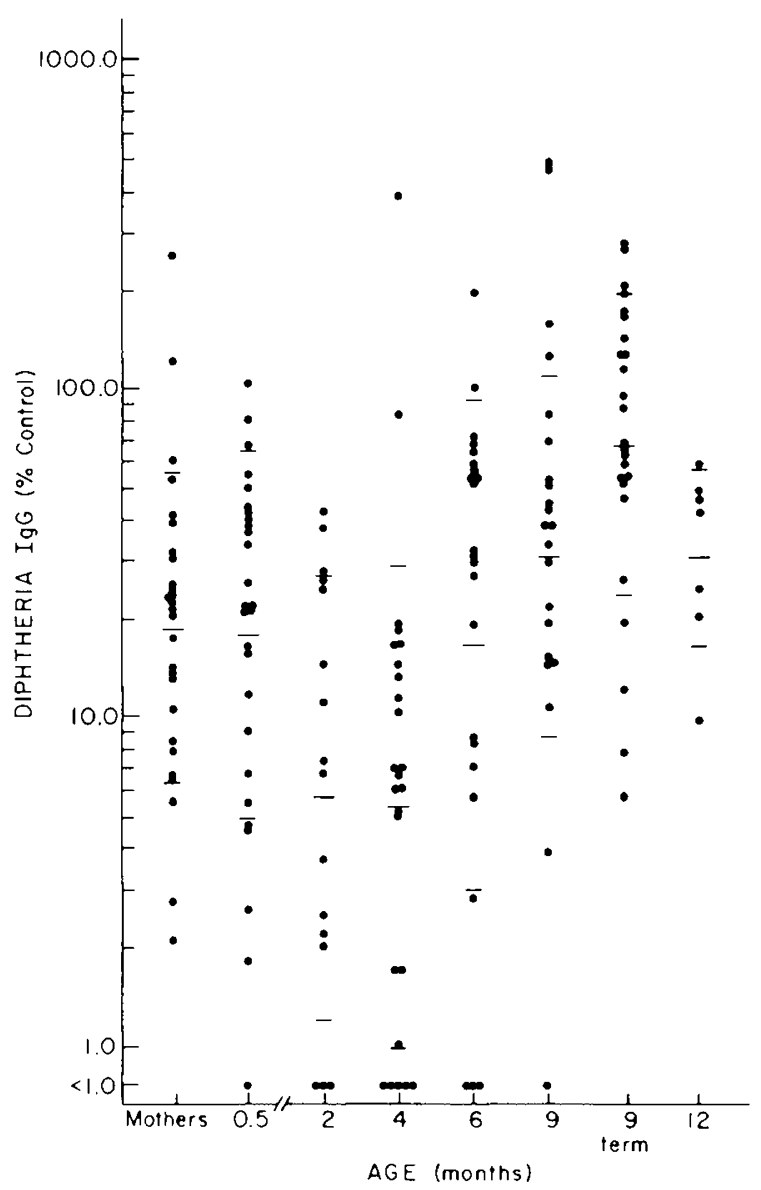

Fig. 2. Plasma diphtheria IgG concentrations (see legend to Fig. 1).

$=19$ pairs, $r=0.86, p<0.001$ ). In contrast, there was no correlation between maternal and preterm infant values at 9 months chronological age, after three doses of DTP (tetanus: $n$ $=27$ pairs, $r=-0.314, p=0.11$; diphtheria: $n=25$ pairs, $r=$ $0.12, p=0.57$ ). Similarly, as would be expected from the lack of correlation between maternal and 9-month infant samples, there was no correlation between infant geometric mean tetanus or diphtheria IgG antibody concentrations at birth and those at 9 months ( $n=19$ paris, tetanus: $r=-0.356, p=0.13$; diphtheria: $r=0.032, p=0.61$ ), suggesting that passively acquired maternal antibody did not inhibit the infants' antibody response to immunization.

Plasma opsonic activity for coagulase negative staphylococcus. The nature of the opsonic requirements for the test strain of coagulase negative staphylococcus is demonstrated by results of a representative experiment shown in Table 3. There was relatively poor uptake of staphylococci by PMN after opsonization with human complement or heat-inactivated PHS alone, compared with PHS which had been stored in aliquots at $-70^{\circ} \mathrm{C}$ preserve complement activity, or heat-inactivated PHS plus complement. Heat-inactivated PHS was absorbed on an IgM Isolation System (Isolab, Inc., Akron, OH) to remove about $95 \%$ of its IgG content, leaving about $90 \%$ of the original IgM. In the presence of complement, opsonic activity of the absorbed PHS was comparable to that of complement alone (Table 3). In contrast, in the presence of complement, an IgG pool which contained $>99 \%$ IgG (14), generously provided by Dr. John R. Schreiber, Albany Medical College and Dr. George R. Siber) had opsonic activity comparable to that of PHS tested at the same or greater concentrations of total IgG. These data suggested that the heat-stable factor required for optimal plasma opsonic activity was IgG antibody.
Table 3. Opsonic activity for coagulase-negative staphylococcus

\begin{tabular}{lc}
\multicolumn{1}{c}{ Opsonin } & \% Control uptake* \\
\hline C $\dagger$ & 18 \\
$\Delta \ddagger$ PHS $\S$ & 34 \\
PHS & 110 \\
$\Delta$ PHS + C & 100 \\
$\Delta$ Absorbed $\|$ PHS + C & 19 \\
IgGף $(3.1 \mathrm{mg} / \mathrm{dl})+\mathrm{C}$ & 91 \\
$\operatorname{IgG}(6.25 \mathrm{mg} / \mathrm{dl})+\mathrm{C}$ & 100 \\
$\operatorname{IgG}(12.5 \mathrm{mg} / \mathrm{dl})+\mathrm{C}$ & 129 \\
$\operatorname{IgG}(25 \mathrm{mg} / \mathrm{dl})+\mathrm{C}$ & 127 \\
$\operatorname{IgG}(50 \mathrm{mg} / \mathrm{dl})+\mathrm{C}$ & 100 \\
$\operatorname{IgG}(100 \mathrm{mg} / \mathrm{dl})+\mathrm{C}$ & 100 \\
$\operatorname{IgG}(200 \mathrm{mg} / \mathrm{dl})+\mathrm{C}$ & 107
\end{tabular}

* Uptake of radiolabeled staphylococci by $10 \% \Delta$ PHS and $5 \%$ complement was assigned a value of $100 \%$ for this experiment and other results are expressed as a percentage of this control value (see text).

$\dagger$ Complement (final concentration, 5\%).

$\$$ Heat-inactivated.

$\S$ PHS (final concentration, $10 \%$ ).

\| Absorbed to remove IgG, leaving IgM (see text).

I Purified IgG (see text).

In contrast to tetanus and diphtheria IgG levels, in the newborn period, the premature infants' mean plasma opsonic activity for coagulase negative staphylococcus was significantly lower than that of their mothers $(53.5 \pm 20.1 \%$ control uptake versus 97.0 $\pm 12.5 \%, p<0.001$, Table 4 and Fig. 3). Opsonic activity fell in the first $3 \mathrm{wk}$ of life, and began to rise again at 4 months chronological age. At 8 and 11 months, it was comparable to that of 9 -month-old term infants $(p=0.27$ and 0.59 , respectively). Mean opsonic activity of both 11 -month-old preterm and 9-month-old term infants was lower than that of the preterm infants' mothers ( $p=0.02$ and $<0.001$, respectively).

There was no correlation between gestational age and staphylococcal opsonic activity at birth $(r=0.221, p=0.18)$; nor was there a correlation between maternal levels and preterm infant levels in the newborn period ( $n=28$ pairs, $r=0.17, p=0.38$ ), or infant levels at 8 to 11 months $(n=16$ pairs, $r=0.32, p=$ 0.23 ). Also, there was no correlation between the premature infants' opsonic activity for coagulase negative staphylococcus in the newborn period and that at 11 months of age $(n=23$ pairs, $r=0.134, p=0.55$ ), suggesting that high levels of activity at birth did not adversely affect the ability to produce opsonic antibody for this organism later in the 1 st yr of life.

Because it appeared that the heat-stable opsonic factor for this particular strain of coagulase negative staphylococcus was IgG, we examined the correlation between infants' plasma opsonic activity for this organism and their total plasma IgG concentrations. In 248 plasma samples we found a weak $(r=0.201)$, but significant $(p=0.001)$, correlation between staphylococcal opsonic activity and total IgG concentrations. Since, in the first few weeks of life, most infant IgG is of maternal origin, we reanalyzed the correlation between total plasma IgG and staphylococcal opsonic activity in 156 samples from 38 infants obtained prior to, and including, each infants' lowest IgG value (at about 2 months of age) (1), and then in 130 samples obtained from the lowest IgG value until 11 to 12 months of age. The correlation coefficient $(r)$ between coagulase negative staphylococcal opsonic activity and the initial fall in IgG concentration was 0.095 ( $p=$ $0.24)$, but with the subsequent rise in $\mathrm{IgG}$ was $0.392(p<0.001)$. These data suggested that there was a better correlation between coagulase negative staphylococcal opsonic activity and the infants' own plasma IgG than with transplacentally acquired maternal IgG. The correlation coefficient between the mothers' total plasma IgG and their opsonic activity for this organism was 0.39 $(n=32, p=0.03)$. 
Plasma opsonic activity for $E$. coli. The opsonic requirements for the $E$. coli strain employed are shown in Table 5. As was seen with the staphylococcus (Table 3), there was very little uptake of $E$. coli by PMN in the presence of complement or heat-inactivated PHS alone. We used purified $\operatorname{IgM}$ and $\mathrm{IgG}$, as well as the whole serum from which they were derived (14) to evaluate opsonic activity of $\operatorname{IgM}$ and $\operatorname{IgG}$ antibody. In the absence of complement, these preparations had no significant opsonic activity for $E$. coli (Cates KL, unpublished data). However, in the presence of complement, $10 \%$ heat-inactivated whole serum from which the purified IgM and IgG had been derived (containing $10 \mathrm{mg} / \mathrm{dl}$ of $\operatorname{IgM}$ and $60 \mathrm{mg} / \mathrm{dl}$ of $\mathrm{IgG}$ ) had opsonic activity (110\%) comparable to that of $10 \%$ heat-inactivated control PHS and complement $(100 \%)$. In the presence of complement, purified IgM tested at 2 and $5 \mathrm{mg} / \mathrm{dl}$ had 37 and $49 \%$ control uptake, respectively. Limited availability of IgM precluded testing of

Table 4. Opsonic activity for coagulase-negative staphylococcus

\begin{tabular}{lccccc}
\hline & $\begin{array}{c}\text { Age } \\
(\mathrm{mo})\end{array}$ & $n$ & $\begin{array}{c}\text { Mean } \pm \mathrm{SD} \\
(\% \text { control })^{*}\end{array}$ & $p$ \\
\hline Preterm infants & 0.5 & 39 & $53.5 \pm 20.1$ & \\
& & & & $<0.001$ \\
& 0.75 & 24 & $46.6 \pm 21.4$ & \\
& 1.25 & 31 & $45.7 \pm 25.1$ & \\
1.75 & 20 & $49.4 \pm 33.1$ & \\
& 2.5 & 23 & $45.1 \pm 25.4$ & \\
& 4 & 30 & $60.6 \pm 27.2$ & $<0.02$ \\
& 6 & 26 & $80.4 \pm 25.0$ & $<0.001$ \\
& 8 & 11 & $76.2 \pm 19.7$ & \\
& 11 & 28 & $88.9 \pm 12.4$ & NS \\
Term infants & 9 & 26 & $85.2 \pm 10.7$ & NS $\dagger$ \\
Mothers & & 28 & $97.0 \pm 12.5$ & $0.02 \dagger$ \\
& & & & $<0.001 \ddagger$ \\
\hline
\end{tabular}

* Results are expressed as a percentage of the opsonic activity of a normal human serum pool (see text).

$\dagger$ Compared with 11-month-old preterm infants.

$\ddagger$ Compared with 9-month-old term infants. higher concentrations. In contrast, in the presence of complement, purified $\mathrm{IgG}$ tested at concentrations of 10 and $30 \mathrm{mg} / \mathrm{dl}$ had only 5 and $7 \%$ control uptake, respectively.

The premature and term infants had very low levels of opsonic activity for $E$. coli in the newborn period (Table 6 ). In preterm infants, the level rose gradually beginning at 4 months chronological age and, at 8 and 11 months, was comparable to that of 9 -month-old term infants. However, opsonic activity of both groups of infants at those ages was still lower than that of the preterm infants' mothers ( $p<0.001$, Table 6; Fig. 4). There was a good correlation $(r=0.48, p<0.001)$ between the preterm infants' total plasma IgM concentrations and opsonic activity for E. coli.

\section{DISCUSSION}

Previously we reported that VLBW (less than $1500 \mathrm{~g}$ ) preterm infants develop severe prolonged hypogammaglobulinemia in the first few months of life $(1,2)$. Compared with term infants who have a mean plasma IgG level of $427 \mathrm{mg} / \mathrm{dl}$ (range 2061125 ) at 4 to 6 months of age (18), at 4 months chronological

Table 5. Opsonic activity for $E$. coli

\begin{tabular}{lccc}
$\begin{array}{c}\text { Opsonin } \\
(\mathrm{mg} / \mathrm{dl})\end{array}$ & \% Control uptake* & $\begin{array}{c}\text { IgM } \\
(\mathrm{mg} / \mathrm{dl})\end{array}$ & $\begin{array}{c}\mathrm{IgG} \\
(\mathrm{mg} / \mathrm{dl})\end{array}$ \\
\hline $\mathrm{C} \dagger$ & 2 & 0 & 0 \\
$\Delta \ddagger$ PHS & 16 & $\mathrm{NT} \|$ & $\mathrm{NT}$ \\
$\Delta$ PHS + C & 100 & $\mathrm{NT}$ & $\mathrm{NT}$ \\
$\Delta$ Serum $+\mathrm{C}$ & 110 & 10 & 60 \\
IgM + C & 37 & 2 & 0 \\
IgM + C & 49 & 5 & 0 \\
IgG + C & 5 & 0 & 10 \\
IgG + C & 7 & 0 & 30 \\
\hline
\end{tabular}

* Uptake of radiolabeled $E$. coli by $10 \% \Delta$ PHS and $5 \%$ complement was assigned a value of $100 \%$ and other results are expressed as a percentage of this control value (see text).

$\dagger$ Complement (final concentration, 5\%).

$\ddagger$ Heat-inactivated.

$\S$ PHS (final concentration, 10\%).

\| Not tested.

I Whole serum from which purified $\operatorname{IgM}$ and $\operatorname{IgG}$ were derived (final concentration, $10 \%$ ).

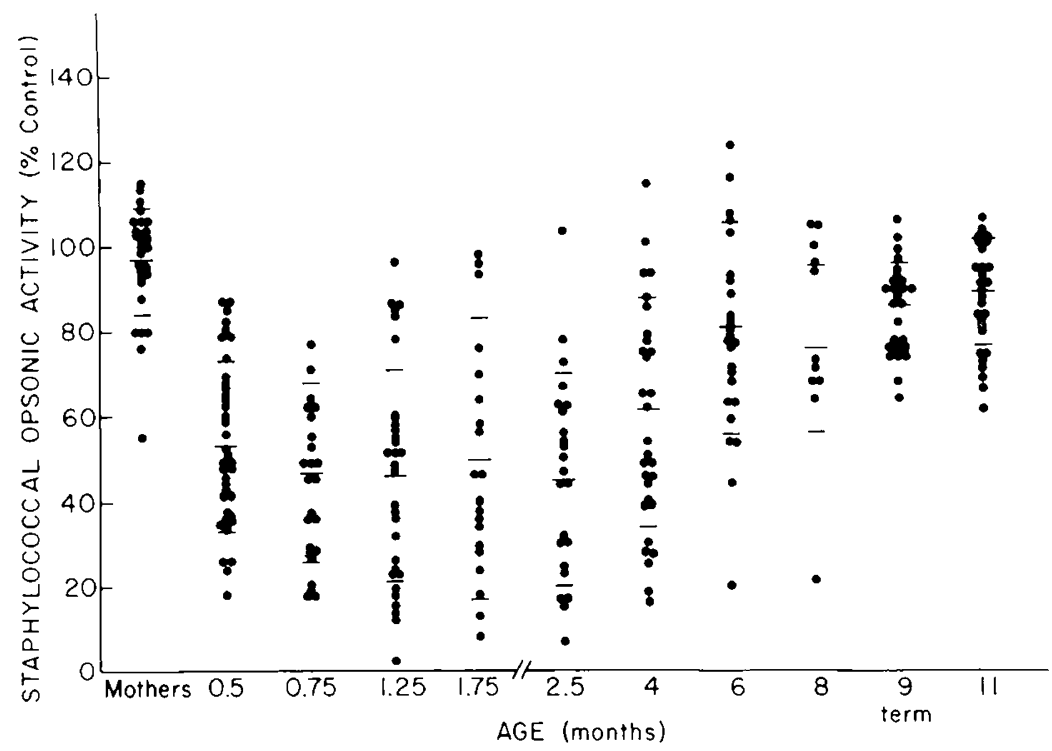

Fig. 3. Plasma opsonic activity for coagulase negative staphylococcus in very small premature infants, in their mothers, and in 9-month-old term infants. Bars represent mean $\pm 1 \mathrm{SD}$. 
age, all of our preterm infants had $\mathrm{IgG}$ levels of less than 200 $\mathrm{mg} / \mathrm{dl}$ and more than two-thirds had levels less than $100 \mathrm{mg} / \mathrm{dl}$. By 6 months, more than $60 \%$ of the preterm infants still had IgG levels of less than $200 \mathrm{mg} / \mathrm{dl}$ (1). The present study was undertaken in order to determine whether these preterm infants could make specific antibodies despite their profound hypogammaglobulinemia. We found that VLBW preterm infants were capable of producing specific $\mathrm{IgG}$ antibody in response to immunization with tetanus and diphtheria toxoids. In addition, by 8 to 11 months chronological age, the preterm infants had developed levels of functional opsonic activity for an IgG-dependent strain of coagulase negative staphylococcus and an IgMdependent strain of $E$. coli which were comparable to those of 9-month-old term infants.

Bernbaum et al. (19) previously reported the response of preterm infants to DTP immunization. Our study differs from theirs in that we examined the changes in absolute levels of tetanus and diphtheria $\mathrm{IgG}$ antibody in preterm infants over the 1st yr of life, not the percentage of infants who developed "protective" levels of antibody, especially since this relatively small amount of antibody $(0.01 \mathrm{U} / \mathrm{ml})$ is found in most preterm

Table 6. Opsonic activity for E. coli

\begin{tabular}{llrcr}
\hline & $\begin{array}{c}\text { Age } \\
(\mathrm{mo})\end{array}$ & \multicolumn{1}{c}{$n$} & $\begin{array}{c}\text { Mean } \pm \text { SD } \\
(\% \text { Control })^{*}\end{array}$ & $p$ \\
\hline Preterm infants & 0.5 & 28 & $5.3 \pm 3.2$ & \\
& 0.75 & 6 & $4.7 \pm 1.9$ & \\
& 1.25 & 22 & $5.2 \pm 2.7$ & \\
& 1.75 & 4 & $5.2 \pm 2.9$ & \\
& 2.5 & 12 & $6.0 \pm 3.3$ & \\
& 4 & 19 & $13.4 \pm 17.9$ & \\
& 6 & 17 & $23.8 \pm 20.9$ & \\
Term infants & 8 & 7 & $37.8 \pm 39.4$ & \\
& 11 & 13 & $62.8 \pm 17.1$ & \\
Newborn & 10 & $7.5 \pm 2.7$ & \\
Mothers & 9 & 37 & $50.9 \pm 27.2$ & $>0.1 \dagger$ \\
\hline
\end{tabular}

${ }^{*}$ Results are expressed as a percentage of the opsonic activity of the normal human serum pool (see text).

+ Compared with 8- or 11-month-old preterm infants.

$\ddagger$ Compared with 9 -month-old term or 11 -month-old preterm infants. infants even after only the first dose of vaccine (19; and present study). We also quantitated tetanus and diphtheria IgG antibodies in order to compare the ability of preterm infants to make specific antibody with that of term infants.

We found that tetanus and diphtheria $\operatorname{IgG}$ antibody levels in newborn preterm infants were comparable to those of their mothers. Einhorn et al. (20) reported that IgG subclass 1 antibody is preferentially transferred across the placenta. They found that term infants' IgG1 levels were almost twice those of their mothers, whereas, IgG2 levels were similar in infants and their mothers. Approximately $90 \%$ of tetanus IgG antibody is subclass 1 $(21,22)$. Therefore, it is possible that even though total IgG levels are significantly lower in preterm infants than their mothers (1), tetanus and diphtheria IgG antibody levels are not lower because of preferential transport of IgG subclass 1 antibodies. The decline in transplacentally derived tetanus and diphtheria IgG antibody paralleled the decline in these infants' total plasma IgG concentrations in the first few months of life (1). The preterm infants' rate of antibody production overcame the rate of catabolism of maternal antibody, on average, only after the third dose of vaccine for tetanus IgG, and after the second dose of diphtheria IgG. After the lowest levels were reached, all infants developed tetanus IgG antibody levels $\geq 0.01 \mathrm{U} / \mathrm{ml}$ as measured by ELISA. Also, all of the infants had diphtheria IgG antibody levels $>1 \%$ of control, which correspond to approximately 0.01 diphtheria antitoxin $\mathrm{U} / \mathrm{ml}$. After three doses of DTP vaccine, the preterm infants' tetanus and diphtheria IgG levels remained significantly lower than those of term infants who had received three doses of vaccine, and their tetanus, but not diphtheria, IgG levels were lower than their mothers'. (The low maternal levels of diphtheria antibodies, compared to those of full term infants at 9 months of age, probably reflect that the mothers had received tetanus, but not diphtheria boosters.) However, the preterm infants clearly were capable of forming specific antibody in response to challenge with these two antigens.

There have been conflicting reports as to whether or not passive transport of maternal tetanus or diphtheria antibody interferes with the infants' response to immunization with the respective antigen (23-26). We found no correlation between maternal or newborn preterm infant tetanus and diphtheria IgG antibody levels, and the antibody levels to these antigens at 9 months of age. These data suggest that maternally derived tetanus and diphtheria IgG antibodies do not infiuence the infants' response to these antigens upon immunization with DPT.

The two organisms used in the opsonic assays were chosen

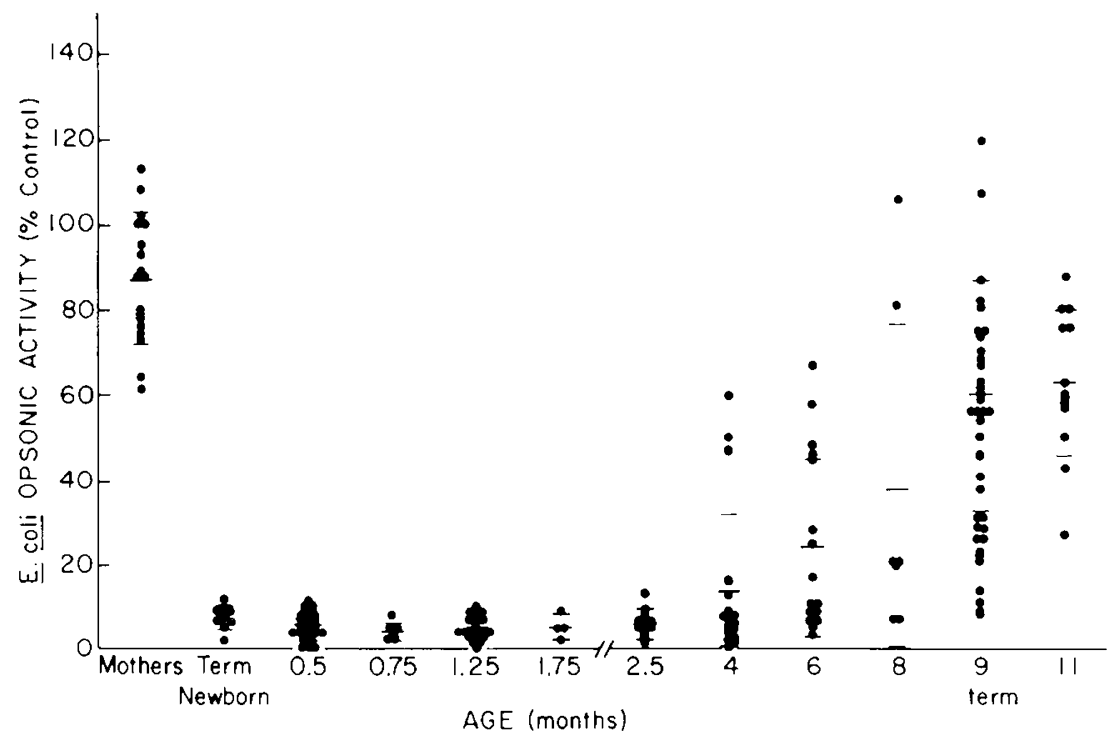

Fig. 4. Plasma opsonic activity for $E$. coli in very small premature infants, in their mothers, and in newborn and 9-month-old term infants. Bars represent mean $\pm 1 \mathrm{SD}$. 
because of their ubiquitous nature and their ability to be opsonized by most normal individuals. Whereas, many adults and most infants lack good antibody levels for such known pathogens as K1-positive $E$. coli (27) or group B streptococci (28), most normal adults have functional serum opsonic activity for nonK1 E. coli (29) and coagulase negative staphylococci (30). In addition, newborn infants rapidly become colonized with both of these organisms.

In vitro opsonic requirements of coagulase negative staphylococci vary (31), but many strains require both heat-stable and heat-labile factors. The test isolate used in this study required a heat-stable plasma factor in addition to complement for most efficient opsonization. We found that this factor was predominantly $\mathrm{IgG}$, as is the case for most gram-positive organisms which require heat-stable opsonins (32).

The pattern of development of the preterm infants' opsonic activity for the coagulase negative staphylococcus in the 1st yr of life was similar to that of total IgG (1), and that for IgG antibody to tetanus and diphtheria toxoids in that there was an initial fall in opsonic activity, followed by a rise with age. However, the pattern of staphylococcal opsonic activity differed from that of tetanus and diphtheria IgG not only in that the preterm infants' mean level of staphylococcal opsonic activity in the newborn period was significantly lower than that of their mothers, but also in that there was no correlation between maternal and newborn levels.

The effect of placental transport on the function of IgG antibodies has not been examined extensively. Hemming et al. (33) found that maternal IgG opsonins for three types of group B streptococci crossed the placenta and appeared in paired cord specimens from most infants. However, most other studies comparing antibodies in paired infant:mother samples have been quantitative (34), not qualitative (i.e. functional). When function has been studied, the function of newborn infants' antibodies usually has been compared with that of healthy adults, not the infants' own mothers (34). Our finding that newborn opsonic activity for coagulase negative staphylococcus does not correlate with maternal activity corresponds with the results reported by Fleer et al. (36), and lends further support to their contention that transfer of IgG across the placenta does not necessarily reflect transfer of functional antibody. It is possible that the good correlation between newborn and maternal levels of tetanus or diphtheria IgG antibody, but not opsonic activity for coagulase negative staphylococcus, may reflect the quantitative but not functional nature of the tetanus and diphtheria IgG ELISA assays. Alternatively, it is possible that there is preferential transfer of some IgG subclasses across the placenta. Although most studies have not demonstrated significant differences in the transfer of different IgG subclasses across the placenta (37-41), as was noted above, Einhorn et al. (20), have demonstrated preferential transport of $\mathrm{IgG} 1$ over IgG2 across the placenta in term infants. Another possible explanation for the poor correlation between infant and maternal antibody functional activity that has been suggested by Fleer's group (36), is that the $\operatorname{IgG}$ molecule is damaged in transport across the placenta. A third possibility is that heat-stable factors other than IgG antibody are responsible for opsonization of this organism. However, this is unlikely because we found that, in the presence of complement, purified $\mathrm{IgG}$ antibody had opsonic activity comparable to that of pooled normal human serum containing the same amount of IgG.

The usual screening test for functional IgM antibodies is the measurement of isoagglutinins (42). However, since not all infants develop isoagglutinins (type $A B$ ), and anti-B isoagglutinins are present in only a small proportion of infants by 1 yr of age, we used an assay for detecting IgM opsonic activity for $E$. coli to study functional IgM antibody in our population of preterm infants. In previous studies, no correlation was found between maternal opsonic activity and opsonic activity for Pseudomonas aeruginosa (43), E. coli (43, 44), or Serratia marcescens (44). Many gram-negative organisms require $\operatorname{lgM}$ antibody as well as complement, particularly the alternative pathway, for efficient opsonization $(44,45)$. Thus, the poor opsonic activity of newborn plasma for these organisms can be predicted because of the poor transfer of IgM and alternative pathway complement proteins across the placenta $(11,12,43,44)$. Despite high levels of maternal opsonic activity for $E$. coli and the addition of exogenous complement, opsonic activity for $E$. coli was very poor in both preterm and term infants in the newborn period. Opsonic activity in both groups of infants rose steadily with age, corresponding well with the rise in total plasma $\operatorname{IgM}$ antibody levels. As was seen with staphylococcal opsonic activity, preterm infants' plasma opsonic activity for $E$. coli was comparable to that of 9 -month-old term infants by 8 to 11 months chronological age. Our finding that neither term nor preterm infants developed as much opsonic activity as the preterm infants' mothers could be anticipated by the fact that by 1 yr of age, even term infants' total plasma IgM is only $55 \pm 23 \%$ of adult levels (18).

The results presented herein may be somewhat biased toward representing "healthier" preterm infants because seven infants were withdrawn from the study because of feeding difficulties. It is possible that factors such as poor nutrition may have made those infants more susceptible to later infections or, conversely, that the stress of necrotizing enterocolitis could have stimulated their immune systems. Nevertheless, since the infants who did not tolerate feedings represented only $8 \%$ of the 89 infants enrolled (14\% of the 51 infants followed to at least 6 months of age), we conclude that the ability of most VLBW preterm infants to form specific and functional antibody may place them at lower risk of infection than might be expected from their severe, prolonged hypogammaglobulinemia in the first several months of life (1). Other patients who have similar levels of hypogammaglobulinemia and who cannot form specific antibody, such as those with Bruton's agammaglobulinemia (4) or common variable hypogammaglobulinemia (3), usually require immune serum globulin therapy. However, patients with transient hypogammaglobulinemia of infancy, who are capable of responding to antigenic challenge with the production of specific antibody, do not ordinarily need such therapeutic intervention (5). Although preterm infants have a high rate of serious infections in the NICU, we found that only two of 89 babies enrolled in this study to date have developed invasive bacterial infections after discharge from the nursery, even though they are discharged when their plasma IgG levels are still falling (i.e. about 2 months chronological age) (1). Several infants developed lower respiratory tract infections (1), but it is unclear whether hypogammaglobulinemia or residual lung disease was the more important predisposing factor. It is possible that the ability to produce specific and functional antibodies, may protect premature infants from having as many serious infections as would be expected from the hypogammaglobulinemia alone. Thus, the ability to recognize specific antigens and to form functional antibody may obviate the need for immune serum globulin therapy in most VLBW infants after discharge from the nursery.

Recently, it was reported that there was an inverse correlation between birth weight and age at immunization with DTP vaccine in 103 special care nursery graduates (46). Our finding, as well as that of Bernbaum et al. (19), that VLBW preterm infants respond well to tetanus and diphtheria antigens when administered at approximately the ages recommended by the Committee on Infectious Diseases of the American Academy of Pediatrics (47), suggests that special care nurseries should be more aggressive in developing DTP immunization programs.

Acknowledgments. The authors thank Drs. Martin F. Randolph, Harry Weinerman, and Tom Odinak, and Mrs. Ruby Edelstein and Ms. Ellen Fitzgibbons for their aid in acquiring term infant plasma samples.

\section{REFERENCES}

1. Ballow M, Cates KL, Rowe JC, Goetz C, Desbonnet C 1986 Development of the immune system in very low birth weight (less than $1500 \mathrm{~g}$ ) premature 
infants: concentrations of plasma immunoglobulins and patterns of infections. Pediatr Res 20:899-904

2. Cates KL, Rowe JC, Ballow M 1983 The premature infant as a compromised host. Curr Prob Pediatr 13:1-63

3. Rosen FS, Janeway CA 1966 The gamma globulins. III. The antibody deficiency syndromes. N Engl J Med 275:709-715

4. Bruton OC 1952 Agammaglobulinemia. Pediatrics 9:722-727

5. Tiller TL, Buckley RH 1978 Transient hypogammaglobulinemia of infancy: Review of the literature, clinical and immunologic features of 11 new cases, and long-term follow-up. J Pediatr 92:347-353

6. Dubowitz LMS, Dubowitz V, Goldberg C 1970 Clinical assessment of gestational age in the newborn infant. J Pediatr 77:1-10

7. Sedgwick AK, Ballow M, Sparks K, Tilton RC 1983 Rapid quantitative microenzyme-linked immunosorbent assay for tetanus antibodies. J Clin Microbiol 18:104-109

8. Sparks K, Ballow M 1983 The indirect ELISA for quantitation of specific antibody: Analysis of antibody dilution curves. Diagn Immunol 1:269-275

9. Peterson PK, Wilkinson BJ, Kim X, Schmeling D, Quie PG 1978 Influence of encapsulation on staphylococcal opsonization and phagocytosis by human polymorphonuclear leukocytes. Infect Immun 19:943-949

10. Cates KL, Marsh KH, Granoff DM 1985 Serum opsonic activity after immunization of adults with Haemophilus influenzae type b-diphtheria toxoid conjugate vaccine. Infect Immun 48:183-189

11. Notarangelo LD, Chirico G, Chiara A, Colombo A, Rondini G, Plebani A Martini A, Ugazio AG 1984 Activity of classical and alternative pathways of complement in preterm and small for gestational age infants. Pediatr Res 18:281-285

12. Strunk RC, Fenton LJ, Gaines JA 1979 Alternative pathway of complement activation in full term and premature infants. Pediatr Res 13:641-643

13. Kloos WE, Jorgensen JH 1985 Staphylococci. In: Lennette EH Manual of Clinical Microbiology, 4th ed. American Society for Microbiology, Washington, D.C., pp 143-153

14. Schreiber JR, Barrus V, Cates KL, Siber GR 1986 Functional characterization of human IgG, IgM and IgA antibody directed to the capsule of Haemophilus influenzae type b. J Infect Dis 153:8-16

15. Barkin RM, Samuelson JS, Gotlin LP 1984 DTP reactions and serologic response with a reduced dose schedule. J Pediatr 105:189-194

16. White WG, Barnes GM, Griffith AH, Gall D, Barker E, Smith JWG 1969 Duration of immunity after active immunization against tetanus. Lancet 2:95-96

17. Fraser DJ 1931 Techniques and methods for quantitative determination of diphtheria antitoxin by skin test in rabbits. Trans R Soc Can 25:175-181

18. Stiehm ER, Fudenberg HH 1966 Serum levels of immune globulins in health and disease: a survey. Pediatrics 37:715-727

19. Bernbaum JC, Daft A, Anolik R, Samuelson J, Barkin R, Douglas S, Polin R 1985 Response of preterm infants to diphtheria-tetanus-pertussis immunizations. J Pediatr 107:184-188

20. Einhorn MS, Quinn A, Shackelford PG 1985 Placental transfer of antibody: correlation with subclass composition. Pediatr Res 19:972(abstr)

21. Stevens R, Dichek D, Keld B, Heiner D 1983 IgG $_{1}$ is the predominant subclass of in vivo and in vitro-produced anti-tetanus toxoid antibodies and also serves as the membrane IgG molecule for delivering inhibitory signals to anti-tetanus toxoid antibody-producing B cells. J Clin Immunol 3:65-9.

22. Seppala IJT, Routonen N, Sarnesto A, Mattila PA, Makela O 1984 The percentages of six immunoglobulin isotypes in human antibodies to tetanus toxoid: standardization of isotype-specific second antibodies in solid-phase assay. Eur J Immunol 14:868-875

23. Brown GC, Volk VK, Gottshall RY, Kendrick PL, Anderson HD 1964 Responses of infants to DTP-P vaccine used in nine injection schedules. Public Health Rep 79:585-602

24. Christie A, Peterson JC 1951 Immunization in the young infant: response to combined vaccines: V. Am J Dis Child 81:501-517

25. Peterson JC, Christie A 1951 Immunization in the young infant: response to combined vaccines: VI-X. Am J Dis Child 81:518-529
26. Dengrove J, Lee EJ, Heiner DC, St. Geme JW Jr, Leake R, Baraff LJ, Ward JI $1986 \mathrm{IgG}$ and IgG subclass specific antibody responses to diphtheria and tetanus toxoids in newborns and infants given DTP immunization. Pediatr Res 20:735-739

27. Cross AS, Zollinger W Mandrell R Gemski P Sadoff J 1983 Evaluation of immunotherapeutic approaches for the potential treatment of infections caused by K1-positive Escherichia coli. J Infect Dis 147:68-76

28. Vogel LC, Boyer KM, Gadzala CA, Gotoff SP 1980 Prevalence of type-specific group B streptococcal antibody in pregnant women. J Pediatr 96:1047-1051

29. Peterson PK, Verhoef J, Schmeling D, Quie PG 1977 Kinetics of phagocytosis and bacterial killing by human polymorphonuclear leukocytes and monocytes. J Infect Dis 136:502-509

30. Peterson PK, Verhoef J, Sabath LD, Quie PG 1976 Extracellular and bacterial factors influencing staphylococcal phagocytosis and killing by human polymorphonuclear leukocytes. Infect Immun 14:496-501

31. Verhoef J, Peterson PK, Kim Y, Sabath LD, Quie PG 1977 Opsonic requirements for staphylococcal phagocytes: heterogeneity among strains. Immunology 33:191-197

32. Peterson PK, Wilkinson BJ, Kim Y, Schmeling D, Douglas SD, Quie PG 1978 The key role of peptidoglycan in the opsonization of Staphylococcus aureus. $\mathrm{J}$ Clin Invest 61:597-609

33. Hemming VG, Hall RT, Rhodes PG, Shigeoka AO 1976 Assessment of group B streptococcal opsonins in human and rabbit serum by neutrophil chemiluminescence. J Clin Invest 58:1379-1387

34. Boyer KM, Papierniak CK, Gadzala CA, Parvin JD, Gotoff SP 1984 Transplacental passage of IgG antibody to group B streptococcus serotype la. J Pediatr 104:618-620

35. Marodi L, Leijh PCJ, Braat A, Daha MR, van Furth R 1985 Opsonic activity of cord blood sera against various species of microorganism. Pediatr Res 19:433-436

36. Fleer A, Gerards LJ, Aerts P, Westerdaal NAC, Senders RC, van Dijk H Verhoef J 1985 Opsonic defense to Staphylococcus epidermidis in the premature neonate. J Infect Dis 152:930-937

37. Morell A, Skvaril F, Hitzig WH, Barandun S 1972 IgG subclasses: development of the serum concentrations in "normal" infants and children. J Pediatr 80:960-964

38. Pitcher-Wilmott RW, Hindocha P, Wood CBS 1980 The placental transfer of IgG subclasses in human pregnancy. Clin Exp Immunol 41:303-308

39. Oxelius VA, Svenningsen NW $1984 \mathrm{IgG}$ subclass concentrations in preterm neonates. Acta Paediatr Scand 73:626-630

40. Morrell A, Sidiropoulos D, Herrmann U, Christensen KK, Christensen P, Prellner K, Skvaril F 1986 IgG subclasses and antibodies to group B streptococci in preterm neonates after intravenous infusion of immunoglobulin to the mothers. Pediatr Infect Dis 5:195-197S

41. Morrell A, Sidiropoulos D, Herrmann U, Christensen KK, Christensen P, Prellner K, Fey H, Skvaril F 1986 IgG subclasses and antibodies to group B streptococci, pneumococci, and tetanus toxoid in preterm neonates after intravenous infusion of immunoglobulin to the mothers. Pediatr Res 20:933936

42. Fong SW, Qaqundah BY, Taylor WF 1974 Developmental patterns of ABO isoagglutinins in normal children correlated with the effects of age, sex, and maternal isoagglutinins. Transfusion 14:551-559

43. McCracken GH Jr, Eichenwald HF 1971 Leukocyte function and the development of opsonic and complement activity in the neonate. Am J Dis Child 121:120-126

44. Dossett JH, Williams RC Jr, Quie PG 1969 Studies on interaction of bacteria serum factors and polymorphonuclear leukocytes in mothers and newborns. Pediatrics 44:49-57

45. Michael JG, Rosen FS 1963 Association of "natural" antibodies to gram-

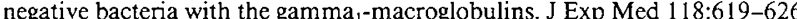

46. Vohr BR, Oh W 1986 Age of diphtheria, tetanus, and pertussis immunization of special care nursery graduates. Pediatrics 77:569-571

47. Peter G 1986 Committee on Infectious Diseases of the American Academy of Pediatrics, 20th ed. American Academy of Pediatrics, Evanston, IL 